\title{
Simplified Analysis of the Effect of Soil Liquefaction on the Earthquake Pile Response
}

\author{
Kotaro Kojima, Kohei Fujita and Izuru Takewaki \\ Department of Architecture and Architectural Engineering, Graduate School of Engineering, Kyoto University, Kyoto 615-8540, \\ Japan
}

\begin{abstract}
The time-history response of a structure-pile system during soil liquefaction is highly complicated and several analytical methods have been proposed through the accuracy verification based on the comparison with the experimental works. However, the analytical methods with higher accuracy often require large computational loads and are not necessarily preferred in the actual design practice. On the other hand, while the response spectrum method is not accurate compared to the aforementioned methods, it can provide useful design guidelines in the preliminary stage for structure-pile systems under soil liquefaction with acceptable accuracy. In this paper, the previously proposed response spectrum method for a structure-pile-soil system is used where the effect of soil liquefaction is taken into account by introducing the so-called $p$-multiplier method. It is shown that, while in the case of inner partial liquefaction with a non-liquefied layer at the top, the demand on the pile moment is large due to the inertial effect of that non-liquefied layer at the top, in the case of overall liquefaction near the ground surface, the demand is smaller than the case of inner partial liquefaction.
\end{abstract}

Key words: Soil liquefaction, response spectrum method, structure-pile-soil system, complex modal combination, kinematic effect, inertial effect.

\section{Introduction}

Since the 1964 Niigata earthquake [1], soil liquefaction is one of the major subjects in the field of earthquake geotechnical engineering. While pile foundations are effective for settlement of buildings during and after liquefaction, its resistance in laterally spreading ground during soil liquefaction is not necessarily clear. Actually during the 1995 Hyogoken-Nanbu (Kobe) earthquake, many reports on damaged piles were provided [2-4].

In the evaluation of pile bending moments, both the effect of the forced displacement of a free-field ground and the effect of the inertial force from a superstructure have to be considered in an appropriate manner (for example Refs. [5-13], as shown in Fig. 1). However, these two effects have different characteristics and it

Corresponding author: Izuru Takewaki, Dr., research fields: soil-structure interaction, structural optimization and design earthquake ground motion. E-mail: takewaki@archi.kyoto-u. ac.jp. seems difficult to include these in a simple way keeping a reasonable accuracy. This is because the analysis of the overall system is usually required in evaluating the latter effect. Conventionally two methods (static method and finite element method [14]) have been used in practice. In the static method, a seismic deformation mode of the surface ground is assumed for evaluating the kinematic effect which is input to the soil-pile system and an assumed inertial force is applied to the soil-pile system for evaluating the inertial effect. However, the static method has a difficulty in its accuracy and the finite element method has some problems, e.g., huge computational resources, complicated input data preparation.

The time-history response of a structure-pile system during soil liquefaction is highly complicated and several analytical methods have been proposed through the accuracy verification based on the comparison with the experimental works (Fig. 2). However, the analytical methods with higher accuracy often require 


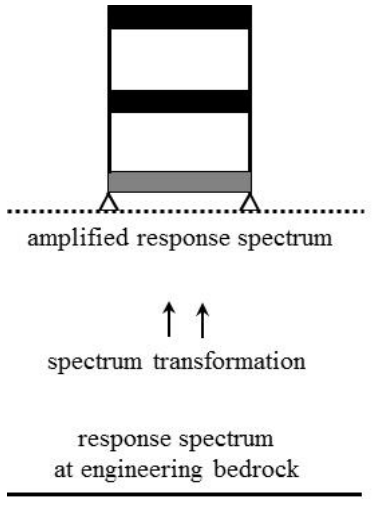

(a)

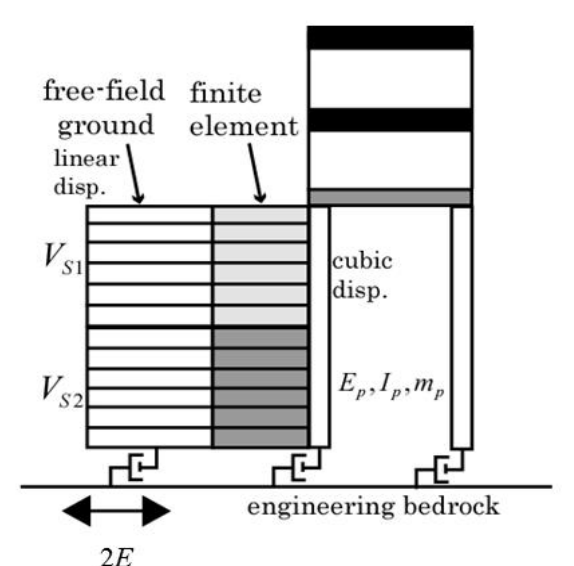

(b)

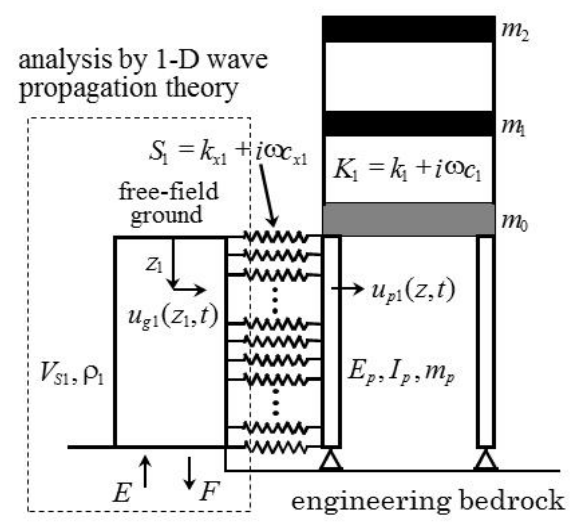

(c)

Fig. 1 Three approaches to using these acceleration response spectra at the engineering bedrock surface: (a) amplification of response spectrum; (b) overall interaction system; (c) substructure model subjected to multiple inputs.

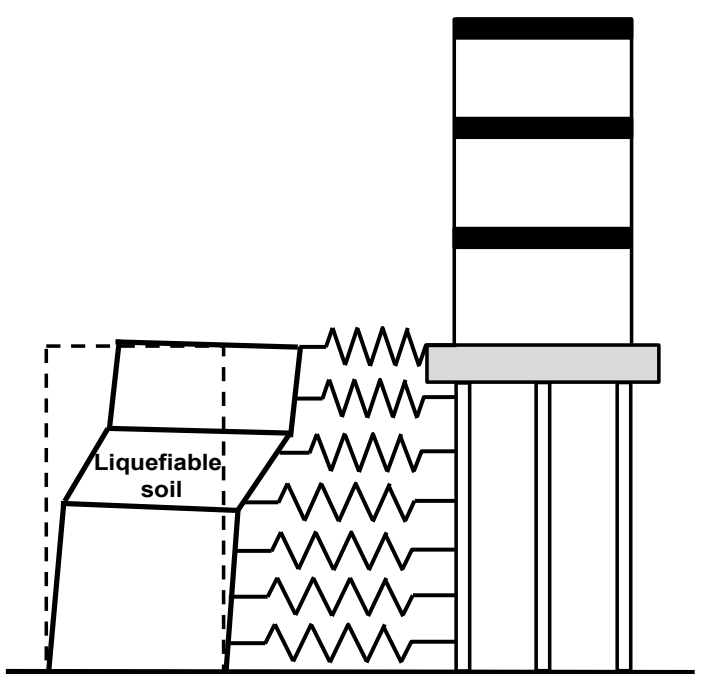

Fig. 2 Building-pile-soil system supported by free-field ground with liquefiable soil layer.

large computational loads and are not necessarily preferred in the actual design practice. On the other hand, although the response spectrum method is not accurate compared to the aforementioned methods, it may be able to provide useful design guidelines in the preliminary stage for structure-pile systems under soil liquefaction with acceptable accuracy.

In this paper, the previously proposed response spectrum method [12, 15-17] in terms of complex modal quantities for a structure-pile-soil system is used where the effect of soil liquefaction is taken into account by introducing the so-called $p$-multiplier method [13]. This response spectrum method is based on the result for superstructures $[18,19]$. The $p$-multiplier method introduces a reduced coefficient for the $p-y$ relation. It is shown that, in the case of inner partial liquefaction with a non-liquefied layer at the top, the demand on the pile moment is large due to the inertial effect of that non-liquefied layer at the top and, in the case of overall liquefaction near the ground surface, the demand is smaller than the case of inner partial liquefaction. The reliability and accuracy of the single-input response spectrum method with the help of the $p$-multiplier method are investigated through the comparison with the result by the time-history response analysis including the multi-input from the free-field ground and the nonlinear restoring-force characteristics around the pile.

\section{Response Spectrum Method in Terms of Complex Modal Quantities}

The mean value of the maximum bending moment and shear force at the pile head may be evaluated by:

$$
M_{\max }=\sqrt{\sum_{i=1}^{n} \sum_{j=1}^{n}\left\{Z_{s}^{(i)} \rho_{s s}^{(i j)} Z_{s}^{(j)}+2 Z_{s}^{(i)} \rho_{s c}^{(i j)} Z_{c}^{(j)}+Z_{c}^{(i)} \rho_{c c}^{(i j)} Z_{c}^{(j)}\right\}}
$$




$$
Q_{\max }=\sqrt{\sum_{i=1}^{n} \sum_{j=1}^{n}\left\{Y_{s}^{(i)} \rho_{s s}^{(i j)} Y_{s}^{(j)}+2 Y_{s}^{(i)} \rho_{s c}^{(i j)} Y_{c}^{(j)}+Y_{c}^{(i)} \rho_{c c}^{(i j)} Y_{c}^{(j)}\right\}}
$$

where,

$$
\begin{aligned}
& Z_{s}^{(i)}=E I \times S_{D s}^{(i)} \operatorname{Re}\left[v^{(i)} \kappa^{(i)}\right], Z_{c}^{(i)}=E I \times S_{D c}^{(i)} \operatorname{Re}\left[v^{(i)} \kappa^{(i)}\right] \\
& Y_{s}^{(i)}=E I \times S_{D S}^{(i)} \operatorname{Re}\left[v^{(i)} \zeta^{(i)}\right], Y_{c}^{(i)}=E I \times S_{D c}^{(i)} \operatorname{Re}\left[v^{(i)} \zeta^{(i)}\right]
\end{aligned}
$$

In Eqs. (3) and (4), EI is the bending stiffness of the pile and $\kappa^{(i)}$ is the curvature component at the pile head in the $i$-th complex eigenmode. $\zeta^{(i)}$ is the derivative of the curvature component with respect to the pile axial coordinate at the pile head in the $i$-th complex eigenmode. $S_{D S}^{(i)}$ and $S_{D c}^{(i)}$ are the sine and cosine spectra, respectively, (assumed here to be equal to the displacement response spectrum) and $v^{(i)}$ is the $i$-th complex participation factor. This method has been developed in Refs. [12, 15-17] based on the accomplishments for superstructures [18, 19]. The accuracy and reliability of this method has been confirmed in Refs. [20, 21].

\section{Design Earthquakes at Engineering Bedrock Surface}

After the Hyogoken-Nanbu earthquake in 1995, the Japanese seismic resistant design code has been revised in 2000 which enabled the direct inclusion of the effect of surface grounds. The design earthquake ground motion defined in that code is employed here. Elastic design is required for the damage-limit level motion (the maximum spectral acceleration for damping ratio 0.05 defined for the engineering bedrock surface motion as outcropping motion is $1.6 \mathrm{~m} / \mathrm{s}^{2}$ ) and inelastic design is allowed for the safety-limit level motion (the maximum spectral acceleration for damping ratio 0.05 is $8 \mathrm{~m} / \mathrm{s}^{2}$ ). The design acceleration response spectrum $S_{A}$ (in $\mathrm{m} / \mathrm{s}^{2}$ for damping ratio 0.05 ) in terms of natural period $T$ for the safety-limit level motion may be expressed as:

$$
\begin{aligned}
& S_{A}=3.2+30.0 T \quad(T<0.16 s) \\
& S_{A}=8.0 \quad(0.16 s \leq T \leq 0.64 s) \\
& S_{A}=5.12 / T \quad(0.64 s<T)
\end{aligned}
$$

This design acceleration response spectrum $S_{A}$ for the damage-limit level motion and that for the safety-limit level motion are shown in Fig. 3. This spectrum has a tendency similar to the conventional spectrum [22], i.e., the constant acceleration region and the constant velocity region exist. As the amplification factors from the maximum acceleration and velocity of the input in terms of damping ratios, those (median type) proposed in Ref. [22] are used.

\section{Ground Model}

A surface ground model, referred to as ground model A (rather soft ground) is considered which includes a liquefiable sand layer. The soil profile of this ground model is shown in Fig. 4. The SPT (standard penetration test) values in the soil layers for ground model A are also shown for reference. The mass density of surface soil layers is assumed to be $1.8 \times 10^{3}$

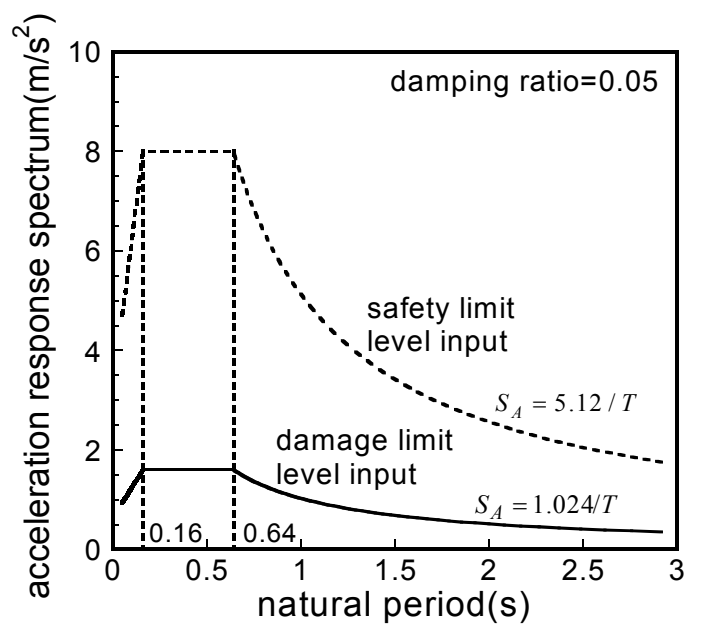

Fig. 3 Two-level acceleration response spectra at engineering bedrock surface for the evaluation of the seismic safety of low and medium-rise buildings lower than $60 \mathrm{~m}$ in Japanese seismic-resistant design code (Standard Building Law in Japan). 


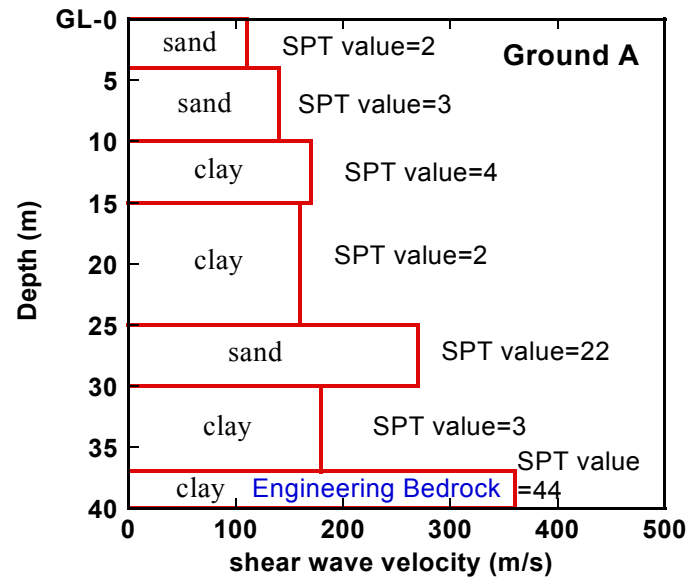

Fig. 4 Soil profile of ground model A and SPT values.

$\mathrm{kg} / \mathrm{m}^{3}$ and Poisson's ratio is 0.45 . The ground model A consists of six soil layers on the engineering bedrock (the mass density is assumed to be $2.0 \times 10^{3} \mathrm{~kg} / \mathrm{m}^{3}$ ). In this ground model, each soil layer has been divided into sub-layers of thickness of $1 \mathrm{~m}$. As a result, the ground model A consists of 38 sub-layers.

To evaluate the strain-dependent nonlinearity of the ground, an equivalent linearization method [16, 23, 24] has been used. The strain-dependent nonlinear relations are shown in Fig. 5 for clay and sand which are taken from the new Japanese seismic-resistant design code revised in June 2000. The effective strain equal to $0.65 \times$ (the maximum strain) is assumed and several iterations are conducted for convergence. The derived stiffness reduction ratios and equivalent

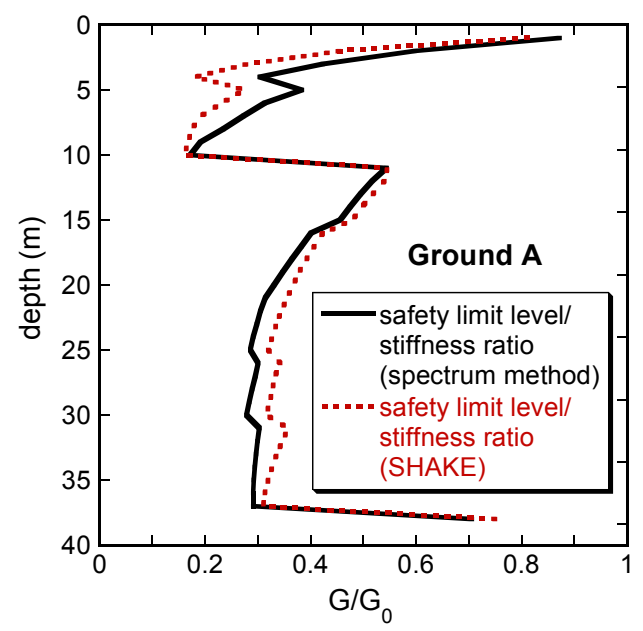

(a) damping ratios by the response spectrum method $[12,16]$ and the SHAKE program [23] for safety-limit level motion are shown in Figs. 6a and 6b, respectively. The fundamental natural period $T_{G}\left(=2 \pi / \omega_{G}\right)$ of the ground model $\mathrm{A}$ is $1.6 \mathrm{~s}$. In case of using the SHAKE program, ground-motion time histories are necessary and ten simulated ground motions have been used $[12,16]$.

The damping ratios derived here are substituted into the term of the hysteretic damping $\beta$ and the following radiation damping is added to those ones $[5,6]$.

$$
\begin{aligned}
& c_{x}=\frac{2 k_{x}}{\omega_{G}}\left\{\frac{\omega_{1} d \rho_{s} V_{s}}{k_{x}}\left[1+\left(\frac{V_{c}}{V_{s}}\right)^{\frac{5}{4}}\right]\left(\frac{\omega_{1} d}{V_{s}}\right)^{-\frac{1}{4}}+\beta\right\} \\
& \left(\omega_{1} \geq 2 \omega_{G}\right)
\end{aligned}
$$

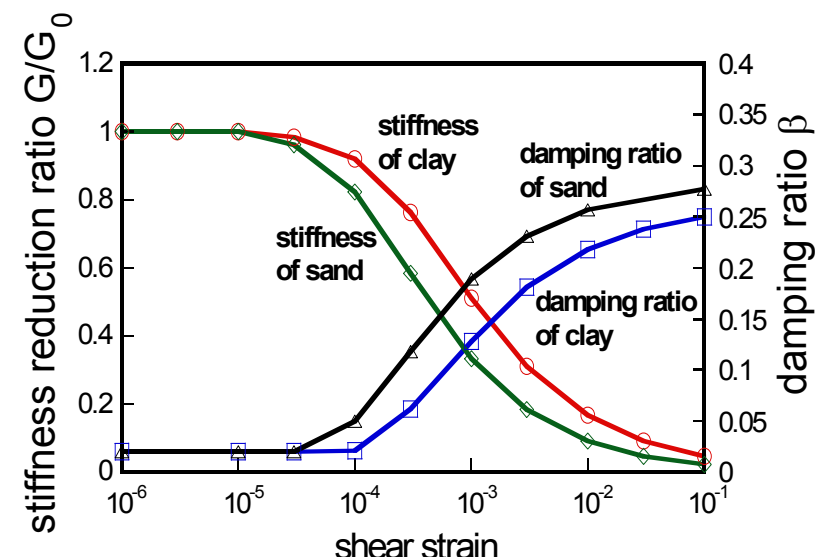

Fig. 5 Dependence of shear moduli and damping ratios on the strain level.

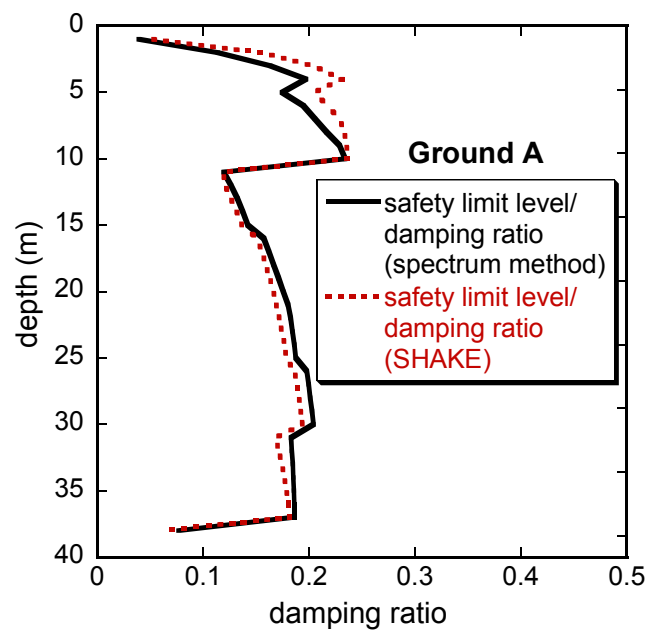

(b)

Fig. 6 Convergent shear modulus ratio to the initial one and damping ratio (safety limit level): response spectrum method and SHAKE for one simulated motion [16]. 
In Eq. (6), $c_{x}, d, \rho_{s}, V_{s}, V_{c}, k_{x}, \omega_{1}, \omega_{G}$ are the damping coefficient of the interaction dashpot, the pile diameter, the soil mass density, the soil shear velocity (strain-dependent equivalent one), the Lysmer's analogue velocity $\left(=V_{s}\right.$ here), the Winkler-type stiffness of the interaction spring (strain-dependent equivalent one), the fundamental natural circular frequency of the superstructure and the fundamental natural circular frequency of the surface ground, respectively. The radiation damping ratio is zero in $\omega_{1} \leq \omega_{G}$ and is linear in $\omega_{G} \leq \omega_{1} \leq 2 \omega_{G}$. The final damping ratio at each soil layer is evaluated at the fundamental natural frequency of the superstructure as a frequency-independent one. These data are used in the computation of the kinematic effect, the inertial effect and the total response. From Figs. 6a and $6 \mathrm{~b}$, it can be seen that the present response spectrum method has a reasonable accuracy compared with the SHAKE program.

The accuracy of the response spectrum method has been demonstrated by the senior author for the total model including the kinematic and inertial effects simultaneously in terms of the transfer functions [12]. A Winkler-type continuum model has been used as another model for comparison [12]. Another comparison has been made with an actual record and the present method has been proven to be accurate enough when taking into account the strain-amplitude nonlinearity of soil deposit [25].

It will be shown in the next section that, by the use of the response spectrum method, the distributions of bending moments and shear forces in piles in the analysis of the kinematic and inertial interactions can be obtained efficiently.

\section{Building Models on Ground Model including a Liquefiable Soil Layer}

2-, 6-, 10-, 16- and 20-story building models are considered. The floor mass of the building for a single pile is $40 \times 10^{3} \mathrm{~kg}$ and the mass of the foundation for a single pile is $120 \times 10^{3} \mathrm{~kg}$. All the building models have been simplified to two-mass models (floor masses are transformed into two masses). A cast-in-place reinforced concrete pile is used and its pile diameter is $1.5 \mathrm{~m}$. The Young's modulus of concrete is $2.1 \times 10^{10}$ $\mathrm{N} / \mathrm{m}^{2}$ and the concrete mass density is $2.4 \times 10^{3} \mathrm{~kg} / \mathrm{m}^{3}$. The fundamental natural periods $T_{B}$ of these models with a fixed base are 0.3, 0.6, 1.0, 1.6 and $2.0 \mathrm{~s}$. Although the responses of superstructures and piles may often be in the plastic range under severe input motions, only elastic responses are considered here for the purpose of investigating the approximate influence of soil liquefaction on pile responses even under the safety-limit level motion. In other words, it may be said that the present procedure corresponds to the elastic response spectrum to measure the input demand.

Consider two liquefaction models (Liquefaction model I and Liquefaction model II) as shown in Figs. 7a and 7b. Liquefaction model I corresponds to the case of inner partial liquefaction with a non-liquefied layer at the top and Liquefaction model II indicates the case of overall liquefaction near the ground surface. A coefficient 1/9 in the $p$-multiplier method has been employed based on the previous research (Table 1) [13]. The coefficient has been multiplied on the equivalent shear modulus of the liquefiable soil (Fig. 6). The coefficient $1 / 9$ is a little bit out of recommendation (recommendation is 0.0-0.10), but it seems reasonable judging from the complicated phenomena during soil liquefaction.

Fig. 8 shows the comparison of the pile bending moments for 2-, 6-, 10-, 16- and 20-story building models between the Liquefaction model I (the coefficient of the $p$-multiplier method $=1 / 9$ ) and the non-liquefaction model. The plot of "kinematic" is computed by giving null masses to the superstructure and foundation floors. On the other hand, the plot "inertial” is obtained by assuming the rigid free-field ground and amplifying the pile bending moment corresponding to the shear force at the pile head (ratio of the shear force for the overall response to that for the rigid free-field ground) [17]. On the other hand, Fig. 9 


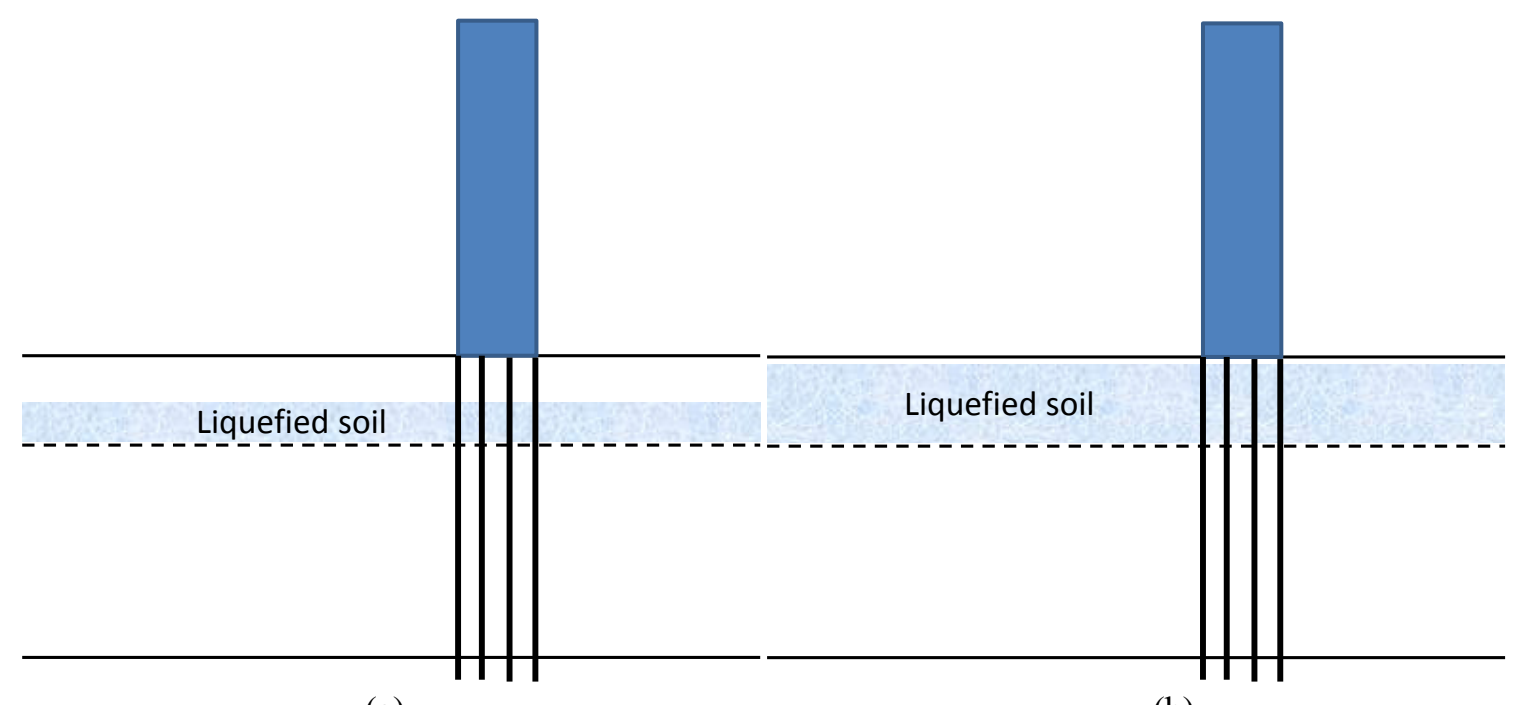

(a)

(b)

Fig. 7 (a) Case of inner partial liquefaction with a non-liquefied layer at the top (Liquefaction model I); (b) Case of overall liquefaction near the ground surface (liquefaction model II).

Table $1 p$-multipliers to account for liquefaction [13].

\begin{tabular}{ll}
\hline SPT value & $p$-multiplier \\
\hline$<8$ & 0.0 to 0.1 \\
$8-16$ & 0.05 to 0.2 \\
$16-24$ & 0.1 to 0.3 \\
$>24$ & 0.2 to 0.5 \\
\hline
\end{tabular}

illustrates the comparison of the pile bending moments for 2-, 6-, 10-, 16- and 20-story building models between the Liquefaction model II (the coefficient of the $p$-multiplier method $=1 / 9)$ and the non-liquefaction model.

It can be observed from Figs. 8 and 9 that Liquefaction model I (inner partial liquefaction with a non-liquefied layer at the top) causes larger pile bending moments than Liquefaction model II (overall liquefaction near the ground surface). It seems that the non-liquefied layer at the top causes a large inertial effect on piles in Liquefaction model I through the tight connection between the free-field ground and the pile.

Fig. 10 presents the comparison of the pile bending moments and shear forces for the two-story building model among the Liquefaction model I (the coefficient of the $p$-multiplier method $=1 / 9)$ and the non-liquefaction model. On the other hand, Fig. 11 shows the comparison of the pile bending moments and shear forces for the two-story building model among the Liquefaction model II (the coefficient of the $p$-multiplier method $=1 / 9$ ) and the non-liquefaction model.

It can be found that both liquefaction models exhibit larger bending moments than the non-liquefaction model. It can also be observed from Figs. 10 and 11 that the Liquefaction model I (inner partial liquefaction with a non-liquefied layer at the top) causes larger bending moments than the Liquefaction model II (overall liquefaction near the ground surface). This may result from the effect of action of the liquefied soil layer near the ground surface on the pile. The softer ground stiffness near the ground surface seems to weaken the action on the pile by reducing the dynamic effect of the liquefied soil in Liquefaction model II.

\section{Comparison with Time-History Response Analysis}

Since it seems important to investigate the accuracy and reliability of the present response spectrum method, a time-history response analysis has been conducted and compared using the multi-input model (Fig. 1c) where the interaction spring is modeled by the Hardin-Drnevich model [26] and the Masing hysteretic 

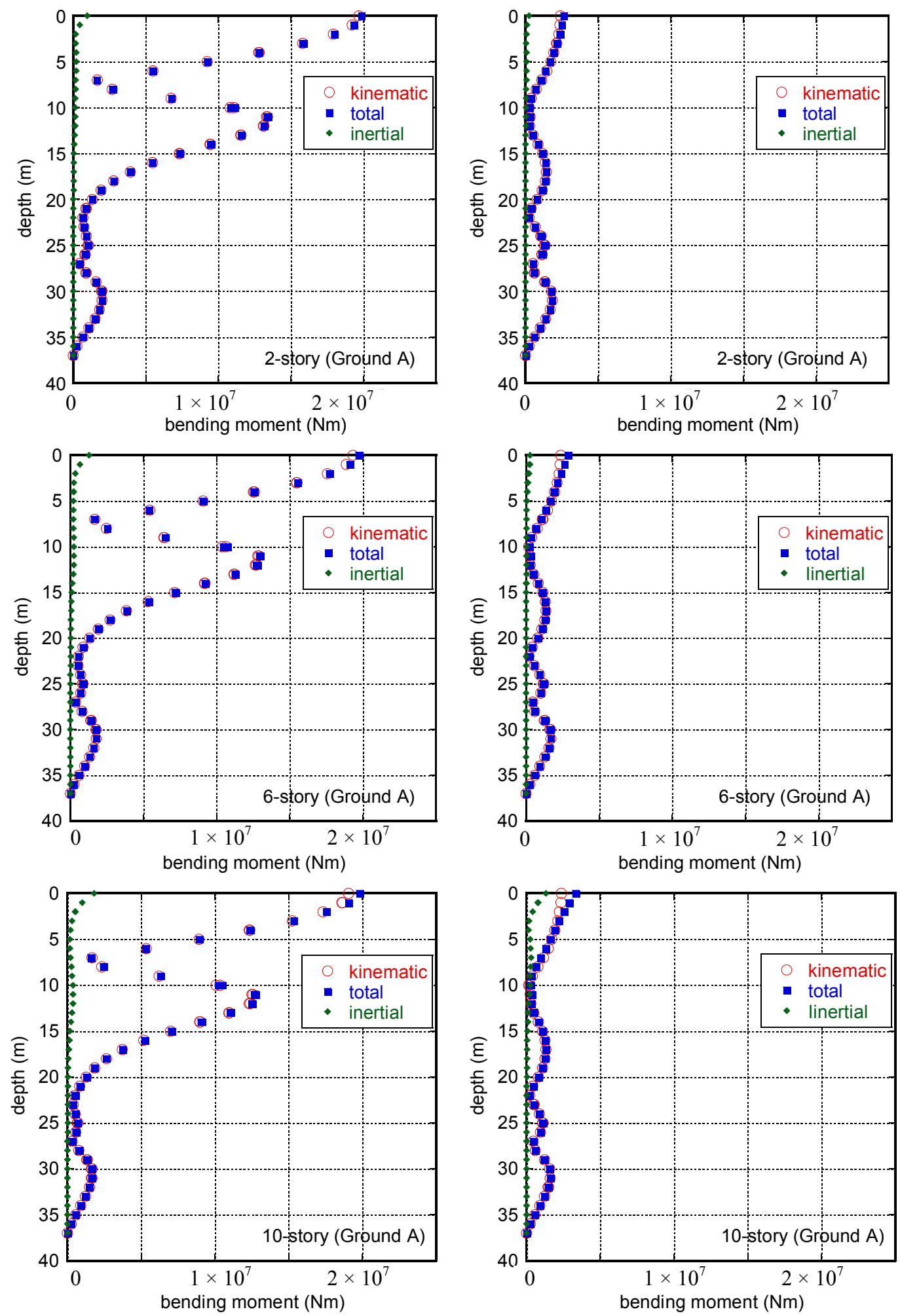

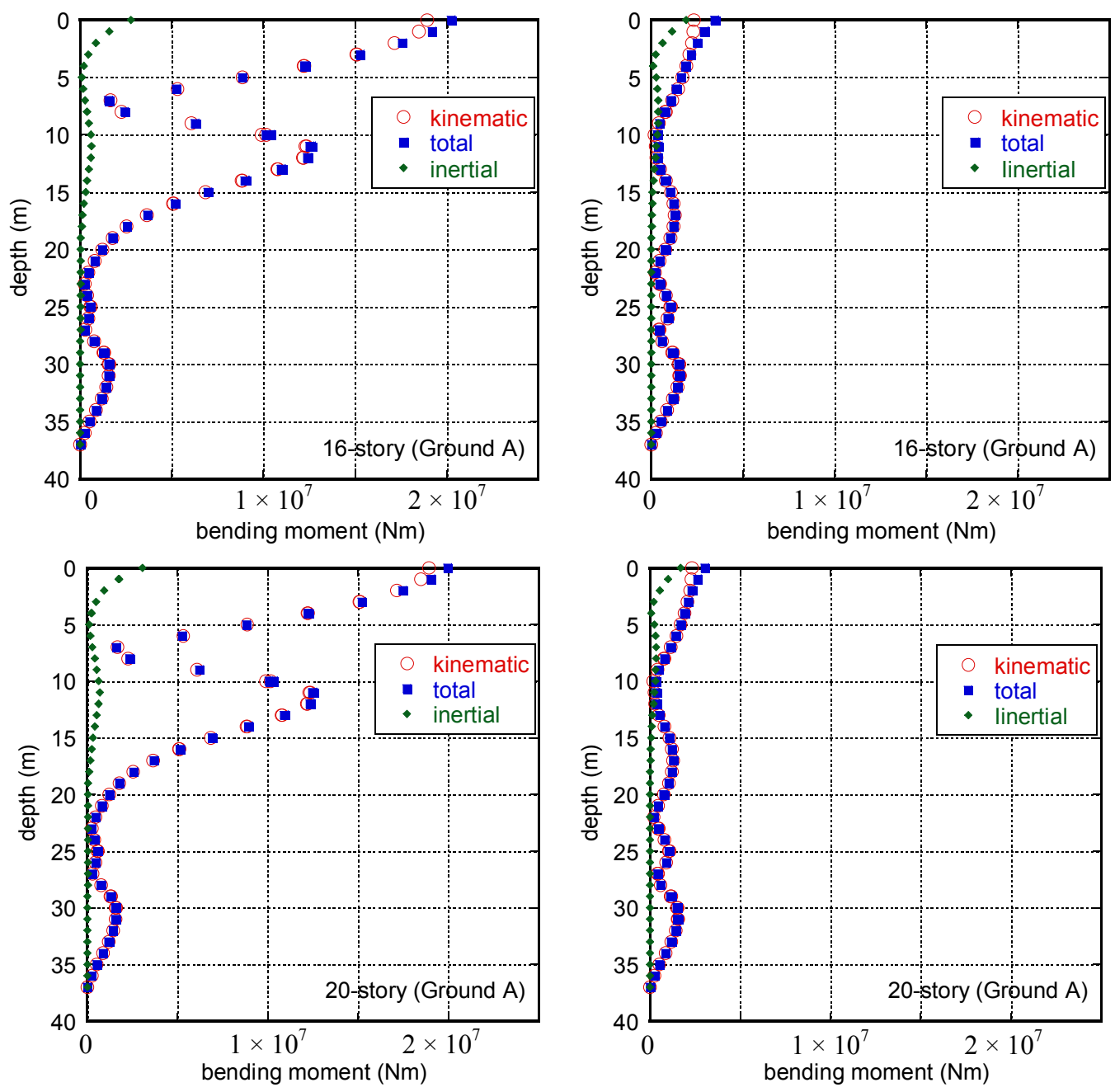

Liquefaction model I

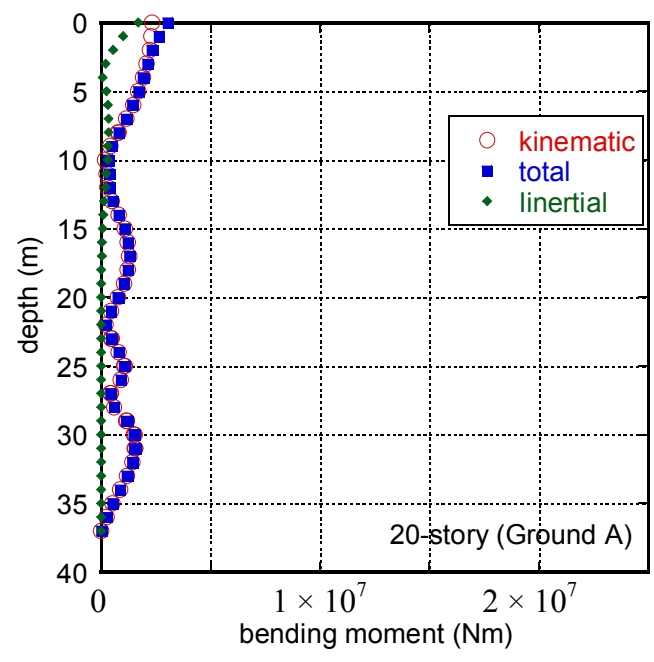

Non-liquefaction model

Fig. 8 Comparison of the pile bending moments for 2-, 6-, 10-, 16- and 20-story building models between the liquefaction model I (left) and the non-liquefaction model (right) (the coefficient of the $p$-multiplier method = 1/9).
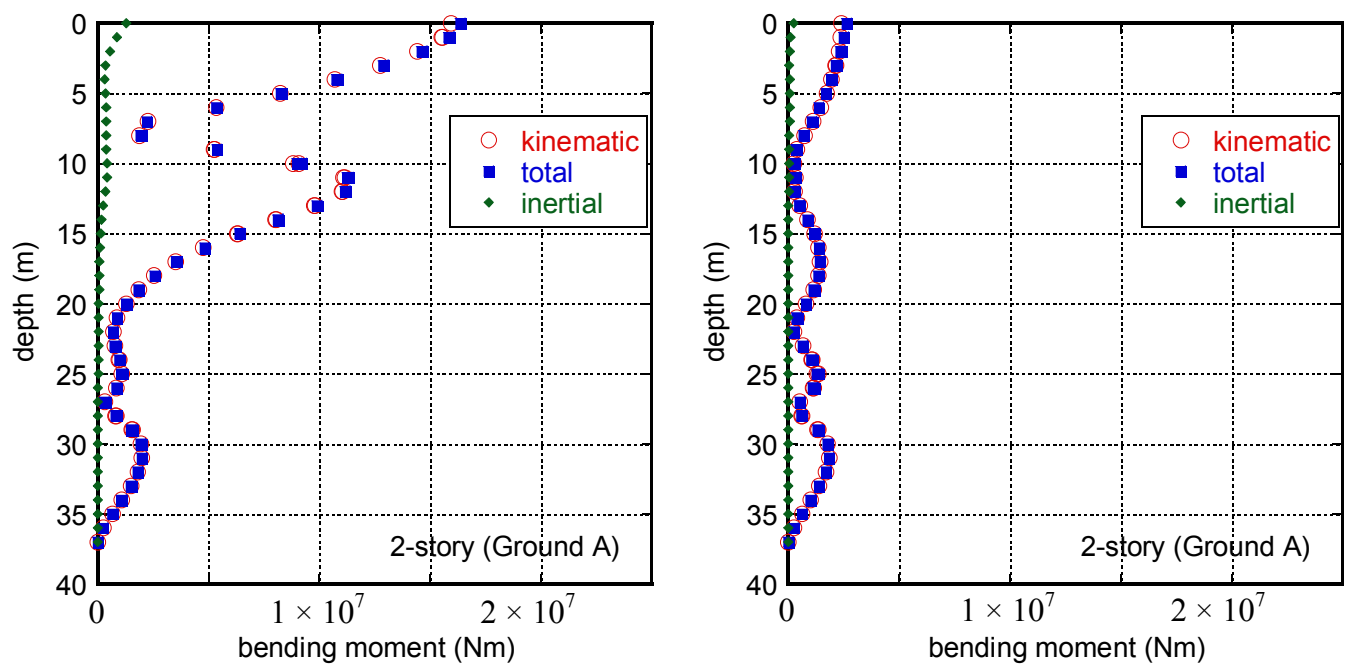

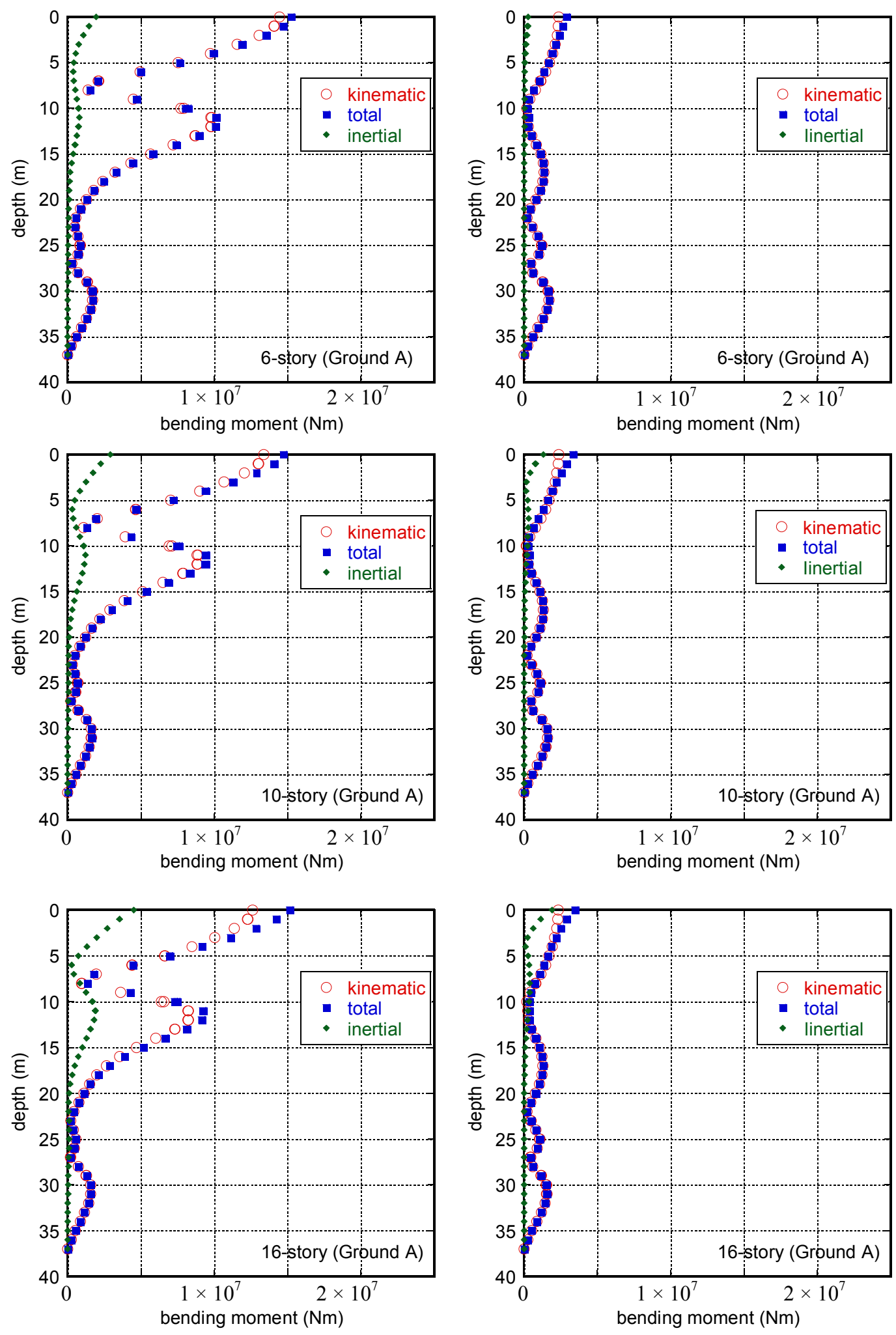

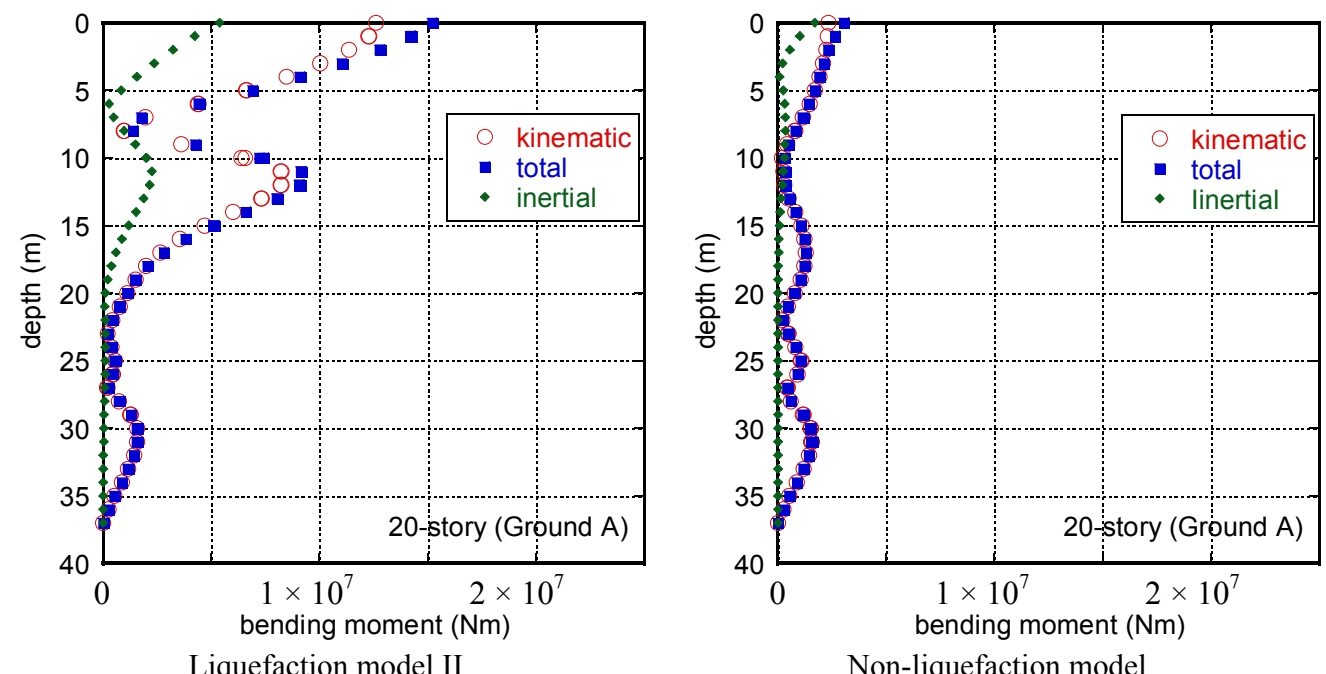

Non-liquefaction model

Fig. 9 Comparison of the pile bending moments for 2-, 6-, 10-, 16- and 20-story building models between the liquefaction model II (left) and the non-liquefaction model (right) (the coefficient of the $p$-multiplier method $=1 / 9$ ).
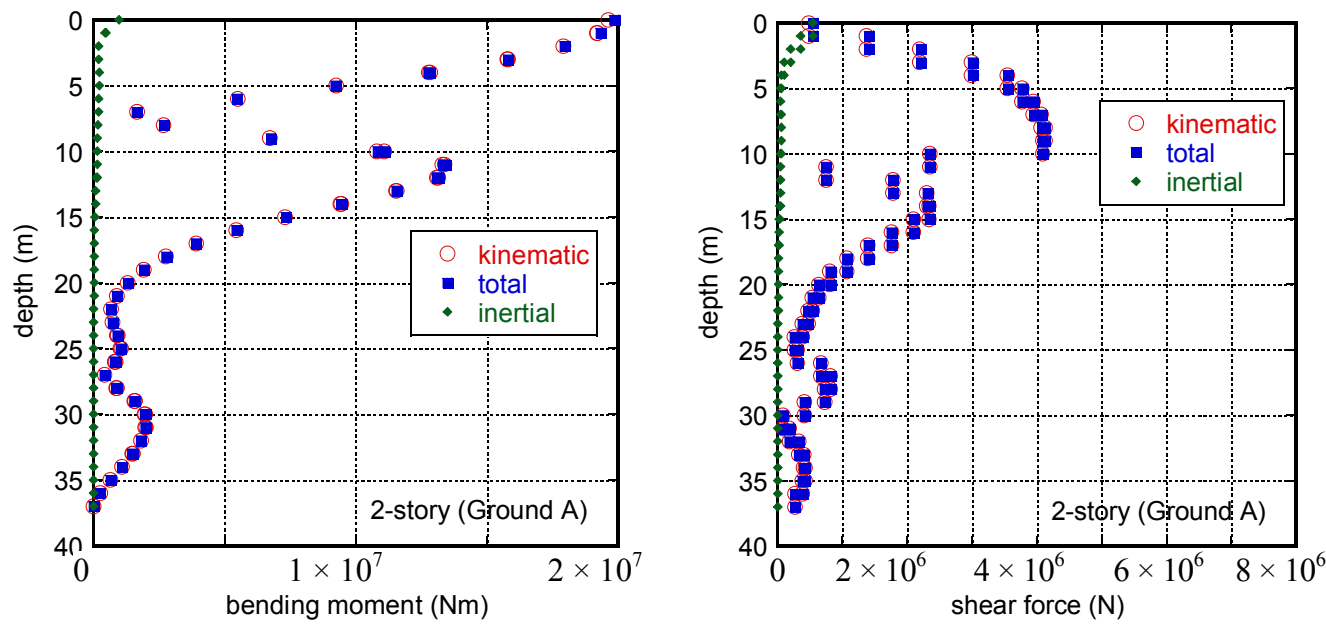

(a) Liquefaction model I (the coefficient of the $p$-multiplier method $=1 / 9$ )
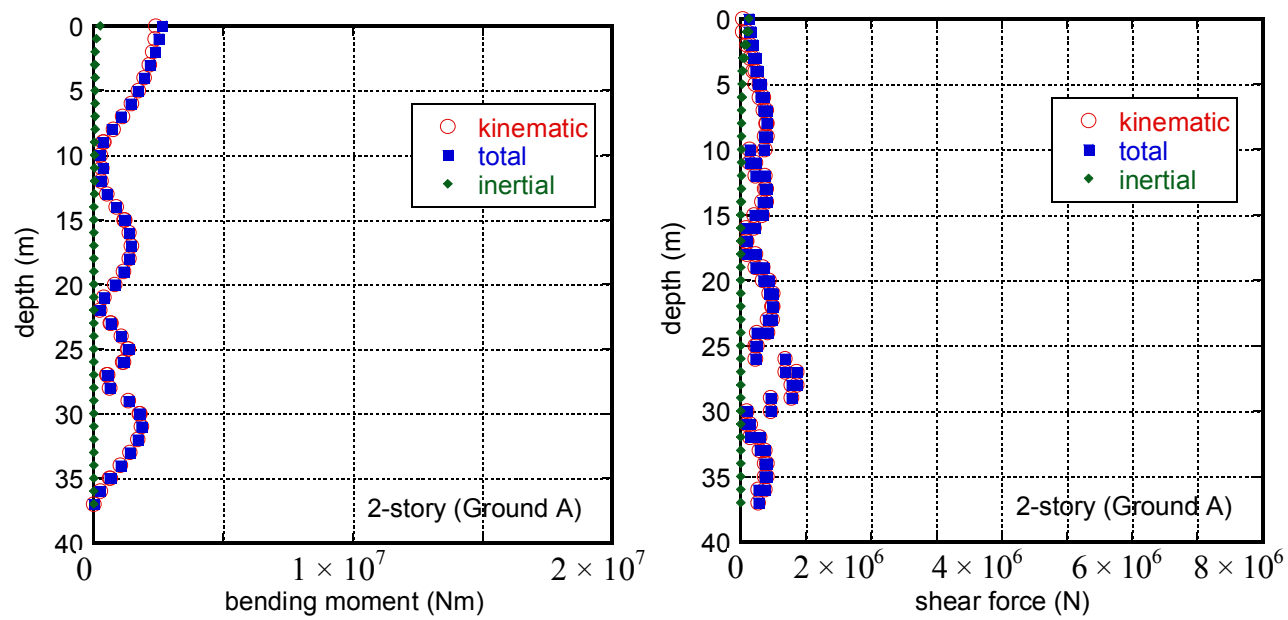

(b) Non-liquefaction model

Fig. 10 Comparison of the pile bending moments and shear forces for the 2-story building model among the liquefaction model I (a) (the coefficient of the $p$-multiplier method $=1 / 9$ ) and the non-liquefaction model $(b)$. 

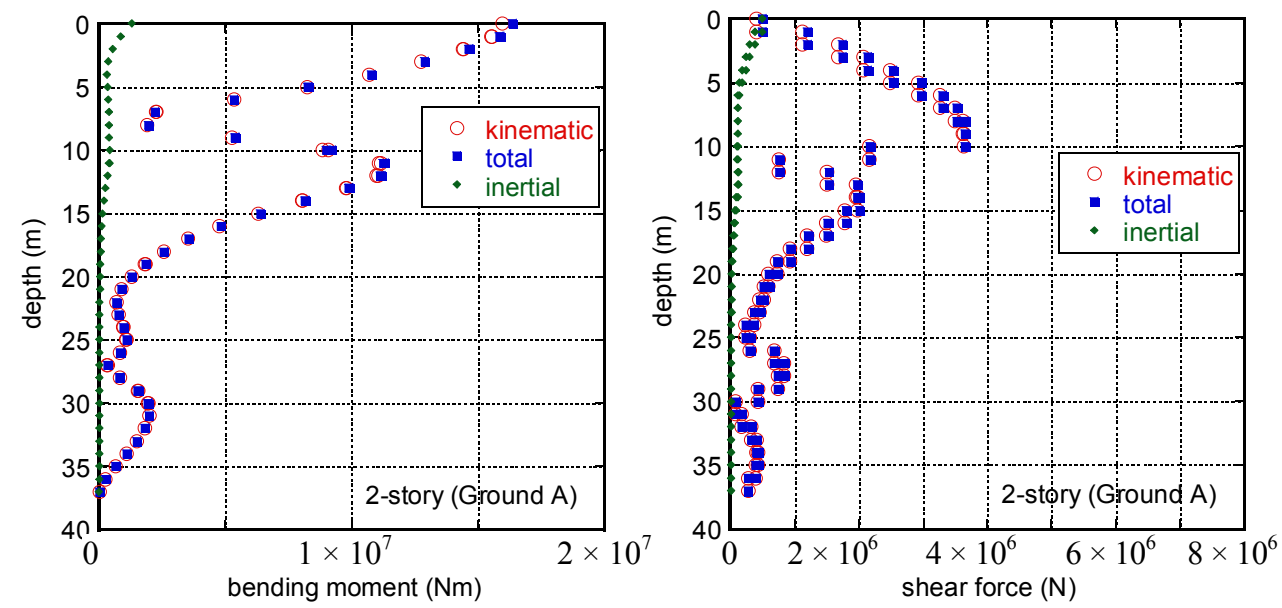

(a) Liquefaction model II (the coefficient of the $p$-multiplier method $=1 / 9$ )
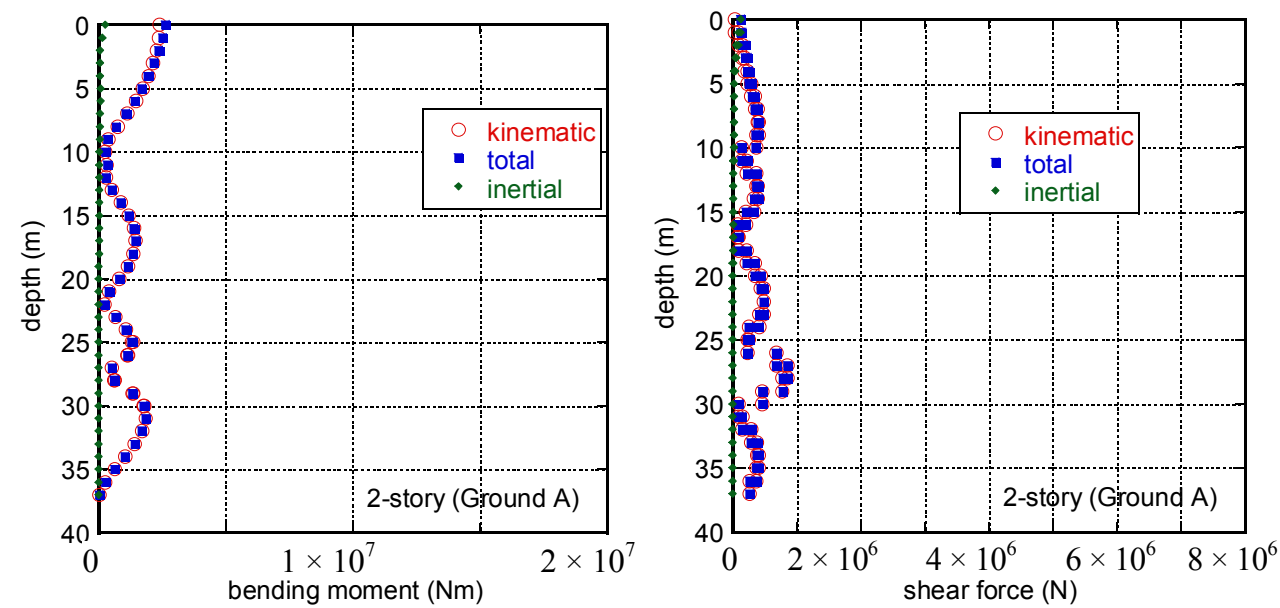

(b) Non-liquefaction model

Fig. 11 Comparison of the pile bending moments and shear forces for the two-story building model among the liquefaction model II (a) (the coefficient of the $p$-multiplier method = 1/9) and the non-liquefaction model (b).

rule. As in the above examples, only elastic responses are considered in superstructures and piles. The coefficient $1 / 9$ has been multiplied on the shear modulus of the liquefiable soil (from GL-4 m to GL-10 $\mathrm{m})$. In the multi-input model, the input ground motions at many depth levels have been generated by using SHAKE program in consideration of this coefficient and the interaction spring has been modeled by taking this coefficient into account.

Fig. 12 shows the comparison of the pile bending moments between the present response spectrum method and a multi-input model including nonlinear horizontal interaction springs placed at every pile node (every $1 \mathrm{~m}$ ) (Liquefaction model I, the coefficient of the $p$-multiplier method $=1 / 9$ ). It can be observed that, while the present response spectrum method provides somewhat different response distributions of pile stresses due to the ensemble-mean characteristic of the response spectrum method, the overall properties can be predicted within an acceptable accuracy. Especially, the bending moment at the pile top exhibits a good correspondence.

\section{Conclusions}

The conclusions may be summarized as follows:

(1) A response spectrum method in terms of complex modal quantities is a useful method for evaluating the overall seismic responses of a building-pile-soil model including a liquefiable soil layer to a ground motion defined at the engineering bedrock surface; 

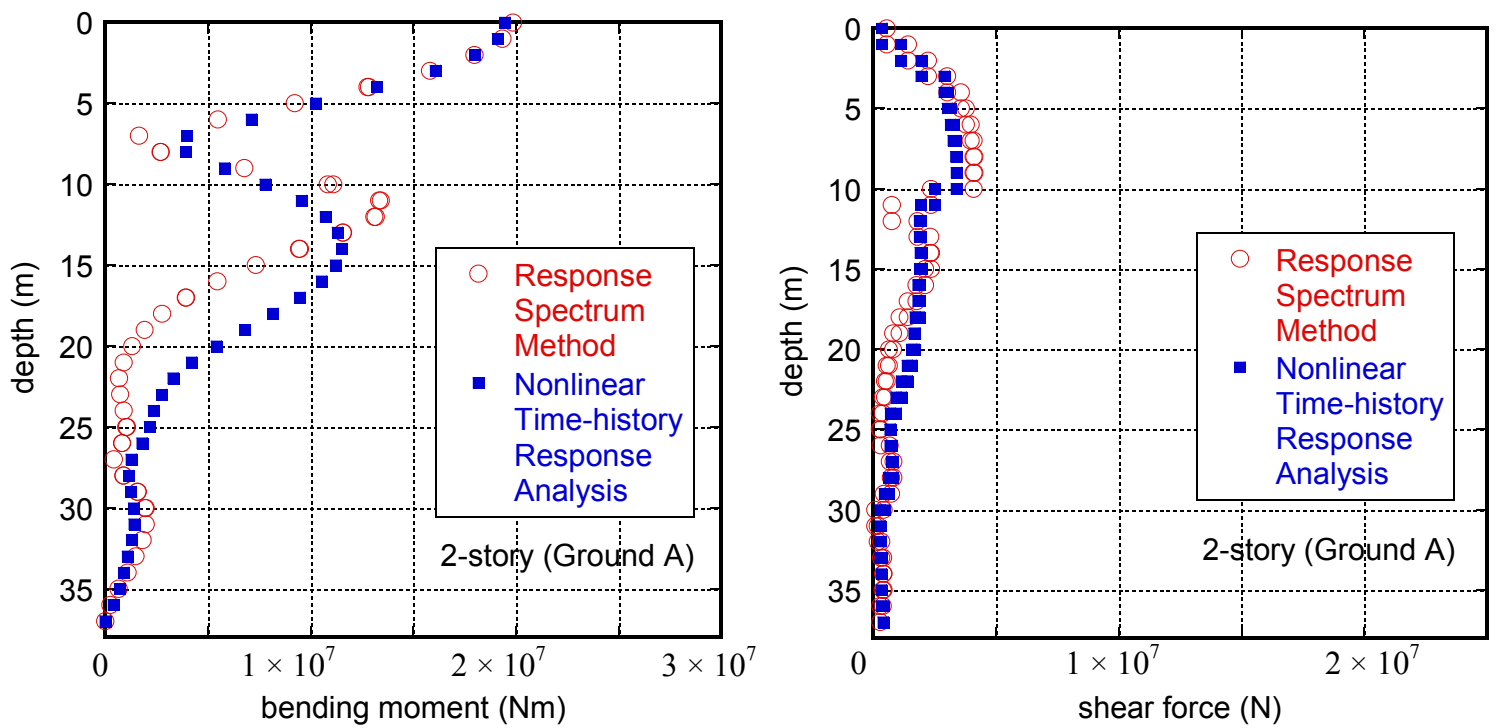

Fig. 12 Comparison of pile bending moments between the present response spectrum method and a multi-input model including nonlinear horizontal interaction springs (Liquefaction model I, the coefficient of the $p$-multiplier method $=1 / 9$ ).

(2) The combination of the response spectrum method with the $p$-multiplier method for evaluating the deterioration of soil resistance in liquefied layers is a simple and effective method. The reliability and accuracy of the $p$-multiplier method have been investigated through the comparison with experimental results in the previous research. The reliability and accuracy of the single-input response spectrum method used in the present paper with the help of the $p$-multiplier method have been verified through the comparison with the result by the time-history response analysis including the multi-input from the free-field ground and the nonlinear restoring-force characteristics around the pile;

(3) While in the case of inner partial liquefaction with a non-liquefied layer at the top, the demand on the pile moment is large due to the inertial effect of that non-liquefied layer at the top, in the case of overall liquefaction near the ground surface, the demand is smaller than the case of inner partial liquefaction.

The detailed response by the time-history response analysis including the multi-input from the free-field ground and the nonlinear restoring-force characteristics around the pile will be shown elsewhere.

\section{Acknowledgments}

Part of the present work is supported by the Grant-in-Aid for Scientific Research of Japan Society for the Promotion of Science (No. 24246095, No. 25630233). This support is greatly appreciated.

\section{References}

[1] I.M. Idriss, R.W. Boulanger, Soil Liquefaction during Earthquakes, EERI (Earthquake Engineering Research Institute), 2008.

[2] Preliminary Reconnaissance report of the 1995 Hyogoken-Nanbu Earthquake, AIJ (Architectural Institute of Japan), Mar. 1995.

[3] Special Issue of Soils and Foundations, Japanese Geotechnical Society, Jan. 1996.

[4] I. Takewaki, Remarkable response amplification of building frames due to resonance with the surface ground, Soil Dynamics and Earthquake Engineering 17 (4) (1998) 211-218.

[5] G. Gazetas, R. Dobry, Horizontal response of piles in layered soils, J. Geotech. Eng. 110 (1) (1984) 20-40.

[6] M. Kavvadas, G. Gazetas, Kinematic seismic response and bending of free-head piles in layered soil, Geotechnique 43 (2) (1993) 207-222.

[7] Y. Miyamoto, A. Fukuoka, N. Adachi, Y. Sako, Pile response induced by inertial and kinematic interaction in liquefied soil deposit, J. Structural Construction Engineering 482 (1996) 53-62. 
[8] G. Mylonakis, A. Nikolaou, G. Gazetas, Soil-pile-bridge seismic interaction: Kinematic and inertial effects, Part I: Soft soil, Earthquake Engineering and Structural Dynamics 26 (1997) 337-359.

[9] Y. Murono, A. Nishimura, Evaluation of seismic force of pile foundation induced by inertial and kinematic interaction, in: Proceedings of 12th World Conference on Earthquake Engineering, Auckland, New Zealand, 2000.

[10] K. Tokimatsu, H. Suzuki, M. Sato, Effects of dynamic soil-structure interaction on pile stress, J. Struct. Construction Eng. 587 (2005) 125-132. (in Japanese)

[11] K. Tokimatsu, H. Suzuki, M. Sato, Effects of inertial and kinematic interaction on seismic behavior of pile with embedded foundation, Soil Dynamics and Earthquake Engineering 25 (2005) 753-762.

[12] A. Kishida, I. Takewaki, Response spectrum method for kinematic soil-pile interaction analysis, Advances in Structural Engineering 13 (1) (2010) 181-197.

[13] S. Ashford, R. Boulanger, S. Brandenberg, Recommended Design Practice for Pile Foundations in Laterally Spreading Ground, PEER (Pacific Earthquake Engineering Research) report, No. PEER 2011/04, 2011.

[14] J. Lysmer, T. Udaka, C.F. Tsai, H.B. Seed, FLUSH: A Computer Program for Rapproximate 3-D Analysis of Soil-Structure Interaction Problems, Earthquake Engineering Research Center report, No. EERC 75-30, University of California, Berkeley, 1975.

[15] T. Nakamura, I. Takewaki, Y. Asaoka, Sequential stiffness design for seismic drift ranges of a shear building-pile-soil system, Earthquake Engineering and Structural Dynamics 25 (12) (1996) 405-420.

[16] I. Takewaki, Response spectrum method for nonlinear surface ground analysis, Advances in Structural Engineering 7 (6) (2004) 503-514.
[17] K. Kojima, K. Fujita, I. Takewaki, Unified analysis of kinematic and inertial earthquake pile responses via single-input response spectrum method, Soil Dynamics and Earthquake Engineering. (in print)

[18] T. Igusa, A.D. Kiureghian, J. Sackman, Modal decomposition method for stationary response of non-classically damped systems, Earthquake Engineering and Structural Dynamics 12 (1) (1984) 121-136.

[19] J.N. Yang, S. Sarkani, F.X. Long, Response spectrum approach for seismic analysis of non-classically damped structures, Engineering Structures 12 (1990) 173-184.

[20] J.L. Tassoulas, E. Kausel, Elements for the numerical analysis of wave motion in layered strata, Int. J. Numerical Methods in Eng. 19 (7) (1983) 1005-1032.

[21] E. Kausel, The thin-layer method in seismology and earthquake engineering, in: Wave Motion in Earthquake Engineering, WIT Press, UK, 2000, pp. 193-213.

[22] N.M. Newmark, W.J. Hall, Earthquake Spectra and Design, Earthquake Eng. Research Institute, Berkeley, 1982.

[23] P.B. Schnabel, J. Lysmer, H.B. Seed, SHAKE: A Computer Program for Earthquake Response Analysis of Horizontally Layered Sites, Pacific Earthquake Engineering Research Center, University of California, Berkeley, 1972.

[24] J.Y. Ching, S.D. Glaser, 1D time-domain solution for seismic ground motion prediction, J. Geotechnical Geoenvironmental Engineering 127 (1) (2001) 36-47.

[25] I. Takewaki, Frequency domain analysis of earthquake input energy to structure-pile systems, Engineering Structures 27 (4) (2005) 549-563.

[26] B.O. Hardin, V.P. Drnevich, Shear modulus and damping in soils: Design equations and curves, J. Soil Mech. Found. Div. 98 (SM7) (1972) 667-692. 